\title{
Pergeseran Komposisi Gulma, Pertumbuhan dan Hasil Jagung Manis dengan Aplikasi Herbisida Campuran
}

\author{
(Shift Composition of Weed, Growth and Results of Sweet Corn \\ with Application of Mixed Herbicides)
}

\author{
Bilman Wilman Simanihuruk \\ Program Studi Agroekoteknologi, Fakultas Pertanian,Universitas Bengkulu \\ bilmanwilmansimanihuruk@yahoo.co.id
}

\begin{abstract}
ABSTRAK
Menurunnya produksi jagung manis perlu dilakukan upaya peningkatan produksi melalui pemanfaatan lahan kering, baik yang telah menjadi lahan pertanian maupun yang belum digunakan. Dalam usaha pemanfaatan lahan kering sering dijumpai kendala sepeti produktivitas cepat menurun, tingkat kesuburan tanah yang rendah dan banyak dijumpai jenis-jenis gulma. Khususnya gulma daun lebar, sempit dan semak berkayu. Percobaan menggunakan Rancangan Petak Terbagi (Split Plot Design). Petak utama adalah dosis glifosat terdiri 3 taraf, yaitu $g_{1}=1,5 \mathrm{l} / \mathrm{ha}, \mathrm{g}_{2}=2 \mathrm{l} / \mathrm{ha}$, dan $\mathrm{g}_{3}=2,5$ l/ha. Anak petak adalah dosis 2,4-D terdiri 3 taraf, yaitu $d_{1}=0,5 \mathrm{l} / \mathrm{ha}, d_{2}=1 \mathrm{l} / \mathrm{ha}, d_{3}=1,5 \mathrm{l} / \mathrm{ha}$. Penggunaan herbisida campuran glifosat dan 2,4-D mampu menggeser komposisi gulma dengan nilai $C$ sebesar 68,75\% pada saat 2 hari sebelum panen. Herbisida glifosat dosis 1,5 l/ha mampu menghasilkan laju pertumbuhan tanaman sebesar $2.23607813 \mathrm{~g} \mathrm{~cm}^{-2} \mathrm{hari}^{-1}$, dan berat tongkol layak jual 129,408 $\mathrm{g}$.
\end{abstract}

Kata kunci : Jagung manis, herbisida, glifosat dan 2,4 D.

\section{ABSTRACT}

The decline in sweet corn production needs to be done to increase production through the use of dry land, both those that have become agricultural land and those that have not been used. In the business of using dry land it is often found that problems such as productivity decline rapidly, low soil fertility and many types of weeds. Especially wide, narrow weed leaves and woody shrubs. Experiment using Split Plot Design. The main plot is the dose of glyphosate consists of 3 levels, namely $g_{1}=1,5 \mathrm{l} / \mathrm{ha}$, $g_{2}=2 \mathrm{l} / \mathrm{ha}$, dan $g_{3}=2,5 \mathrm{l} / \mathrm{ha}$. The subplot is a 2,4-D dose consisting of 3 levels, namely $d_{1}=0,5 \mathrm{l} / \mathrm{ha}, d_{2}$ $=1 \mathrm{l} / \mathrm{ha}, d_{3}=1,5 \mathrm{l} / \mathrm{ha}$. The use of a herbicide mixture of glyphosate and 2,4-D was able to shift the weed composition with a value of $C$ of $68.75 \%$ at 2 days before harvest. Glyphosate herbicide dose of 1.5 l/ha was able to produce plant growth rates of $2.23607813 \mathrm{~g} \mathrm{~cm}-2$ days-1, and the weight of the selling cob was $129,408 \mathrm{~g}$.

Keywords : Sweet corn, herbicides, glyphosate and 2.4 D.

\section{PENDAHULUAN}

Produksi jagung manis pada Tahun 2012 naik, namun Tahun 2013 terjadi penurunan yaitu 19,3 ton di Tahun 2012 dan 18,5 juta ton di Tahun 2013 (BPS, 2013). Menurunnya produksi jagung manis perlu dilakukan upaya peningkatan produksi melalui ekstensifikasi atau intensifikasi untuk memenuhi permintaan konsumen yang semakin meningkat seiring dengan pertambahan jumlah penduduk. Upaya yang dapat dilakukan mengoptimalkan pemanfaatan lahan kering, baik yang telah menjadi lahan pertanian maupun yang belum digunakan.
Dalam usaha pemanfaatan lahan kering sering dijumpai kendala sepeti produktivitas cepat menurun, tingkat kesuburan tanah yang rendah dan banyak dijumpai jenis-jenis gulma. Gulma lahan kering biasanya berdaun lebar dan sempit serta siklus hidupnya semusim dan tahunan (Kurnia, 2004). Gulma dilahan kering apabila pengendaliannya dengan tenaga manusia, dibutuhkan sekitar 15 HOK (hari orang kerja) itu satu orang. Untuk menghemat waktu dan biaya dipandang perlu penggunaan herbisida.

Herbisida menekan pertumbuhan gulma, gulma yang mati berfungsi sebagai 
penutup tanah dan sumber bahan orgaanik yang dapat mempertahankan stabilitas struktur dan produktivitas tanah (Zubaidah et al., 2001). Untuk mengendalikan gulma apabila hanya menggunakan satu jenis herbisida secara terus menerus membuat gulma resisten nantinya sulit mengendalikannya. Guna mengantisipasi kelemahan tersebut upaya yang dapat dilakukan ialah dengan mencampurkan dua jenis bahan aktif herbisida (Umiyati, 2005).

Pencampuran herbisida dapat menurunkan dosis herbisida secara tunggal serta meningkatkan efektivitas pengendalian gulma (Moenandir, 1990). Herbisida berbahan aktif IPA (Isopropilamina glifosat) dan 2,4-D banyak digunakan masyarakat, sehingga banyak formulasi yang menggunakan bahan aktif tersebut. Herbisida berbahab aktif IPA sifatnya non selektif dan cara kerjanya sistemik. Herbisida 2,4-D bersifat selektif dan sistemik menghambat pertumbuhan gulma berdaun lebar (Sembodo, 2010).

Efektivitas pemberian herbisida sangat ditentukan oleh dosis herbisida. Gulma sasaran akan dapat dimatikan jika menggunakan dosis yang tepat, akan tetapi dosis herbisida terlalu tinggi, merusak bahkan mematikan tanaman yang dibudidayakan. Sehingga perlu dilakukan pengujian terhadap kisaran dosis campuran herbisida untuk mengendalikan pertumbuhan gulma daun lebar dan sempit pada lahan kering.

Adapun tujuan penelitian untuk mendapatkan dosis campuran herbisida glifosat dan 2,4-D yang merubah komposisi gulma, pertumbuhan dan hasil jagung manis pada lahan kering. Mendapatkan dosis herbisida glifosat yang merubah komposisi gulma, pertumbuhan dan hasil jagung manis. Mendapatkan dosis herbisida 2,4-D yang merubah komposisi gulma, pertumbuhan dan hasil jagung manis

\section{METODE PENELITIAN}

Penelitian dilaksanakan pada Januari Maret 2015, di Desa Pasar Pedati RT 01, Kecamatan Pondok Kelapa, Kabupaten Bengkulu Tengah, 10 dpl. Bahan yang digunakan benih Bonanza $F_{1} \quad$ (jagung manis), herbisida glifosat dan 2,4-D, Furadan 3G, air. Alatnya ember, meteran, mistar, jangka sorong, tisu, label, pipet ukur $10 \mathrm{ml}$, gelas ukur $1000 \mathrm{ml}$, tugal, patok, tali raffia, bambu, necis, jaring burung, kertas koran, kantong plastic, parang, semprotan kapasitas $5 \mathrm{~L}$, petak kuadrat $(0,5 \mathrm{~m} \times 0.5 \mathrm{~m})$, drum plastik, timbangan analitik, leaf area meter, cangkul, oven dan alat tulis.

Percobaan menggunakan Rancangan Petak Terbagi (Split Plot Design). Petak utama adalah dosis glifosat terdiri 3 taraf, yaitu $\mathrm{g}_{1}=1,5 \mathrm{l} / \mathrm{ha}, \mathrm{g}_{2}=2 \mathrm{l} / \mathrm{ha}$, dan $\mathrm{g}_{3}=2,5$ 1/ha. Anak petak adalah dosis 2,4-D terdiri 3 taraf, yaitu $\mathrm{d}_{1}=0,5 \mathrm{l} / \mathrm{ha}, \mathrm{d}_{2}=1 \mathrm{l} / \mathrm{ha}, \mathrm{d}_{3}=1,5$ 1/ha. Dari kedua faktor diperoleh 9 kombinasi perlakuan, diulang 3 kali. Saat aplikasi masing-masing perlakuan ditambahkan air sebanyak $525 \mathrm{~mL}$ sebagai pengencer.

Lahan penelitian harus ditumbuhi gulma daun lebar dan sempit dengan nilai koefisien komunitas atau nilai $\mathrm{C} \geq 75 \%$. Untuk mendapatkan $\mathrm{C}$ dilakukan analisis vegetasi sebelum tanam, dan dua hari setelah panen. Sebelum aplikasi herbisida glifosat dan 2,4-D, dilakukan kalibrasi terhadap alat semprot dan kebutuhan larutan tiap petak pada setiap kombinasi perlakuan agar pada saat aplikasi tepat dan merata. Aplikasi herbisida campuran glifosat dan 2,4-D dilakukan 2 minggu sebelum benih ditanam. Sebelum tana diambil 100 biji jagung manis yang di uji, apabila semuanya tumbuh atau berkecambah $100 \%$, benih layak dijadikan bahan tanam.

Benih yang ditanam tanahnya diolah hanya pada lubang tanam, saat tanam dilakukan pagi hari kemudian dilanjutkan penyiraman. Penanaman benih pada lubang tanam dibuat bentuk barisan, jarak tanam 25 $\mathrm{cm} \times 75 \mathrm{~cm}$. Tiap lubang 2 benih, penjarangan dilakukan pagi hari, saat tanaman berumur 14-21 HST, adapun tujuan penjarangan untuk memperoleh kepadatan populasi 60 tanaman per petak percobaan.

Penyulaman dilakukan saat berumur 7-10 HST, dengan menyiapkan bibit pada polibag kecil ditanam bersamaan penanaman benih di lahan, apabila ada tanaman mati dan pertumbuhan kurang baik maka 
digantik dengan benih yang sudah disiapkan. Penyulaman bertujuan agar populasi tanaman perpetak tetap terjaga dan seragam. Pembumbunan dilakukan umur $4 \mathrm{mst}$, bertujuan memperkokoh posisi batang sehingga tidak mudah rebah, memperbaiki aerasi tanah, menutup akar dan merangsang tumbuhnya akar-akar baru.

Penyiangan dilakukan dengan mencabut gulma disekitar tanaman saat analisis vegetasi yaitu 3 dan 6 mst bertujuan mengurangi kompetisi gulma terhadap tanaman.

Penyiraman dilakukan setiap hari satu kali yaitu dilakukan sore hari, apabila tidak turun hujan, jika turun hujan pada hari itu tidak disiram. Pengendalin hama dan penyakit tidak dilaksanakan karena tidak ada gejala serangan.

Panen jagung umur 71 HST dicirikan rambut tongkol coklat kehitaman, kering dan lengket atau bila ditekan dengan jari biji mengeluarkan cairan seperti pasta.

Pengamatan gulma melalui analisis vegetasi meliputi identifikasi jenis, perhitungan jumlah dan frekuensi kemunculan gulma pada setiap petak contoh serta berat kering gulma. Analisis vegetasi dilakukan sebelum tanam dan dua hari sebelum panen. Pengamatan jagung adalah Laju Pertumbuhan tanaman (LPT) dan berat tongkol layak jual

Data pengamatan gulma untuk mendapatkan nilai SDR dan C. Data variabel jagung manis dianalisis uji $\mathrm{F}$ pada $5 \%$. Jika berpengaruh nyata pada uji $\mathrm{F}$, dilanjutkan analisis Poynomial Orthogonal taraf 5\% (Gomez and Gomez, 1995).

\section{HASIL DAN PEMBAHASAN}

\section{Analisis Vegetasi}

Lahan penelitian merupakan lahan kering ditumbuhi gulma berdaun lebar dan sempit dengan nilai $\mathrm{C} \geq 75 \%$. Analisis vegetasi awal sebelum aplikasi herbisida nilai $\mathrm{C}$ sebesar $77,55 \%$. Nilai $\mathrm{C}$ di atas $75 \%$ lahan tersebut layak dijadikan lahan penelitian pengendalian gulma apabila lahan penelitian ditumbuhi oleh gulma yang seragam (homogen) dengan nilai $\mathrm{C}$ antar blok > 75\% (Paiman et al., 2012).

Tabel 1. Nilai koefisien komunitas (C) gulma Sebelum aplikasi herbisida dan 2 hari sebelum panen

\begin{tabular}{c|c}
\hline Waktu analisis vegetasi & Nilai C \% \\
\hline Sebelum aplikasi herbisida (SAH) & 77.75 \\
Dua hari sebelum panen & 68.75 \\
\hline
\end{tabular}

Analisis vegetasi 2 hari sebelum panen menunjukkan nilai $\mathrm{C}$ kurang dari $75 \%$, mengindikasikan perubahan komposisi gulma yang sifatnya homogen menjadi heterogen. 
Tabel 2. Nilai SDR gulma sebelum aplikasi herbisida.

\begin{tabular}{lcccc}
\hline \multirow{2}{*}{ Jenis Gulma } & \multicolumn{4}{c}{ SDR (\%) } \\
\cline { 2 - 5 } & I & II & III & rata-rata \\
\hline Borreria latifolia & 20,31 & 14,21 & 10,61 & 15,05 \\
Calopogonium mucunoides & 33,69 & 26,36 & 23.55 & 26,37 \\
Imperata cylindrica & 4,41 & 15,49 & 17,76 & 12,55 \\
Cynodon dactylon (L.) Pers & 9,14 & 7,69 & 9,93 & 8,92 \\
Mimosa pudica L. & 2,42 & 0,00 & 3,32 & 1,91 \\
Melastoma malabathricum & 1,20 & 1,21 & 0,00 & 0,80 \\
Cyperus rotundus & 0,87 & 0,00 & 0,86 & 0,58 \\
Croton hirtus & 9,23 & 10,65 & 13,10 & 11,00 \\
Ischaemum muticum L. & 2,46 & 2,56 & 2,76 & 2,59 \\
Borreria alata & 2,59 & 0,00 & 1,89 & 1,49 \\
Axonopus compressus & 2,33 & 2,95 & 2,27 & 2,52 \\
Chromolaena odorata & 1,29 & 6,08 & 6,62 & 4,66 \\
Mimosa invisa & 4,75 & 0,85 & 0,00 & 1,87 \\
Phyllanthus urinaria & 0,00 & 3,00 & 3,49 & 2,16 \\
Paspalum commersonii L. & 0,00 & 1,89 & 0,00 & 0,63 \\
\hline Total & 100 & 100 & 100 & 100 \\
\hline
\end{tabular}

Maksud komposisi gulma heterogen adalah terjadinya perubahan dinamika populasi gulma yaitu dengan hilangnya spesies gulma lama dan kemudian munculnya spesies gulma baru. Perubahan komposisi gulma, baik gulma lama yang hilang atupun gulma baru muncul diduga akibat perlakuan campuran dosis herbisida glifosat dan 2,4-D. Menurut Utomo et al. (2014) keuntungan dari pencampuran herbisida glifosat dan 2,4 D ialah glifosat dalam keadaan dosis rendah kurang efektif dalam mengendalikan gulma berdaun lebar sedangkan dengan penambahan herbisida 2,4 D mampu mengendalikan gulma dari jenis daun lebar. Selain pengaruh herbisida gulma yang mati dan mengering berubah menjadi mulsa menutupi permukaan tanah sehingga menghambat cahaya matahari yang dibutuhkan gulma untuk tumbuh dan berkembang, berakibat terhahadap pertumbuhan gulma yang baru.

Analisis vegetasi saat 2 hari sebelum panen ada 14 jenis gulma, terdapat perubahan jenis gulma jika dibandingkan dengan analisis vegetasi gulma sebelum aplikasi perlakuan. Gulma Imperata cylindrica tetap dominan saat analisis vegetasi 2 hari sebelum panen dengan nilai SDR $19.91 \%$. Hal ini disebabkan karena Imperata cylindrica dapat beradaptasi pada kondisi ekstrime, sedangkan Calopogonium mucunoides dapat menghambat pertumbuhan Imperata cylindrica mati karena pengaruh aplikasi herbisida sehingga gulma Imperata cylindrica dapat tumbuh dengan baik karena penghambatnya tidak ada. 
Tabel 3. Nilai SDR gulma 2 hari sebelum panen

\begin{tabular}{lcccc}
\hline \multirow{2}{*}{ Jenis Gulma } & \multicolumn{4}{c}{ SDR (\%) } \\
\cline { 2 - 5 } & $\mathrm{I}$ & $\mathrm{II}$ & $\mathrm{III}$ & rata-rata \\
\hline Borreria latifolia & 13,95 & 12,12 & 12,71 & 12,93 \\
Calopogonium mucunoides & 14,71 & 15,57 & 6,07 & 12,11 \\
Imperata cylindrica & 6,40 & 17,73 & 35,59 & 19,91 \\
Cynodon dactylon (L.) Pers & 13,06 & 7,56 & 1,46 & 7,36 \\
Mimosa pudica L. & 0,78 & 0,98 & 0,00 & 0,59 \\
Melastoma malabathricum & 5,39 & 0,00 & 0,00 & 1,80 \\
Cyperus rotundus & 2,10 & 0,00 & 5,48 & 2,53 \\
Croton hirtus & 13,24 & 13,10 & 9,62 & 11,98 \\
Ischaemum muticum L. & 3,87 & 3,03 & 2,79 & 3,23 \\
Borreria alata & 2,86 & 1,24 & 4,38 & 2,83 \\
Axonopus compressus & 11,83 & 15,39 & 8,29 & 11,84 \\
Chromolaena odorata & 2,98 & 2,92 & 1,60 & 2,50 \\
Mimosa invisa & 4,65 & 2,54 & 1,44 & 2,88 \\
Phyllanthus urinaria & 0,07 & 1,61 & 0,00 & 0,56 \\
\hline Total & 100 & 100 & 100 & 100 \\
\hline
\end{tabular}

\section{Analisis varian pengamatan Tanaman Jagung Manis}

Perlakuan dosis glifosat secara tunggal berpengaruh nyata terhadap laju pertumbuhan tanaman (LPT) pada 2-4 mst dan berat tongkol layak jual. Sedangkan perlakuan 2,4-D secara tunggal berpengaruh tidak nyata pada semua variabel pengamatan.

Tabel 4. Hasil analisis varian untuk variabel Laju peertumbuhan tanaman (LPT) dan berat tongkol layak jual jagung (BTLJ) manis

\begin{tabular}{c|c|c|c|c}
\hline \multirow{2}{*}{ Variabel } & \multirow{2}{*}{$\begin{array}{c}\text { Waktu } \\
\text { pengamatan }\end{array}$} & \multirow{2}{*}{$\begin{array}{c}\text { Dosis } \\
\text { glifosat }\end{array}$} & \multicolumn{2}{|c}{ Nilai F hitung 5\% } \\
\cline { 4 - 5 } & & $2,4 \mathrm{~d}$ & interaksi \\
\hline \multirow{3}{*}{ LPT } & $2-4 \mathrm{MST}$ & $12.15^{*}$ & $1.97 \mathrm{~ns}$ & $0.55 \mathrm{~ns}$ \\
\cline { 2 - 5 } & $4-6 \mathrm{MST}$ & $2.75 \mathrm{~ns}$ & $0.20 \mathrm{~ns}$ & $1.16 \mathrm{~ns}$ \\
\cline { 2 - 5 } & $6-8 \mathrm{MST}$ & $0.12 \mathrm{~ns}$ & $0.83 \mathrm{~ns}$ & $1.12 \mathrm{~ns}$ \\
\hline BTLJ & Saat penen & $9.31 *$ & $0.89 \mathrm{~ns}$ & $0.27 \mathrm{~ns}$ \\
\hline
\end{tabular}

Keterangan : * : Berpengaruh nyata pada uji $\mathrm{F}$ taraf 5\%

$\mathrm{ns}$ : Berpengaruh tidak nyata pada uji $\mathrm{F}$ taraf $5 \%$

\section{Laju Pertumbuhan Tanaman (LPT)}

Hasil uji F 5\% laju pertumbuhan tanaman menunjukan bahwa pada peningkatan dosis herbisida glifosat $1,5 \mathrm{l} / \mathrm{ha}$ sampai $2,5 \mathrm{~L} / \mathrm{ha}$ berpengaruh nyata terhadap laju pertumbuhan tanaman (LPT) pada 2-4 mst, pola garis $\mathrm{y}=0.000003 \mathrm{x}^{2}-0.000015 \mathrm{x}$ $+2.236094\left(\mathrm{R}^{2}=0.161\right)($ Gambar 1$)$.

Hasil tertinggi terlihat pada dosis glifosat 1,5 L/ha dengan LPT $2.23607813 \mathrm{~g}$ $\mathrm{cm}^{-2}$ hari $^{-1}$. Hal ini sesuai dengan penelitian Utomo (2014), menyatakan dosis glifosat 1 L/ha sudah mampu menekan pertumbuhan gulma saat 2-4 MST sehingga berpengaruh positif terhadap LPT sebesar $60,14 \%$. Herbisida glifosat bekerja secara sistemik purna tumbuh berbentuk larutan dalam air berwarna kekuningan untuk mengendalikan gulma secara broad spectrum baik gulma berdaun sempit dan gulma berdaun lebar tuntas sampai keakar-akarnya apabila dosisnya tepat (Landerdale and Savannah, 1998). Herbisida glifosat melakukan penetrasi melalui lapisan kutikula daun dan ditranslokasikan bersama air keseluruh bagian tanaman oleh sistem simplas. 
Menurut Mercado (1986), glifosat bergerak dari daun ke rhizome atau akar dan tetap berada dalam tumbuhan sampai semua sistem tumbuhan tersebut mati. Namun peningkatan dosis herbisida dari 1,67 L/ha sampai 2,5 L/ha cenderung menurunkan LPT, hal ini diduga peningkatan dosis herbisida berakibat dapat merubah cara kerja herbisida glifosat. Awalnya bersifat sistemik karena peningkatan dosis maka herbisida tersebut bisa berubah menjadi kontak sehingga tidak tepat sasaran. Adanya dugaan dengan meningkatnya dosis herbisida yang cara kerjanya sistemik juga bisa berubah menjadi ZPT seperti herbisida 2.4 D. Hasil penelitian Faqihhudin et al., (2014) bahwa peningkatan dosis herbisida glifosat diatas 2 liter/ha menurunkan hasil pada pertumbuhan maupun hasil tanaman jagung.

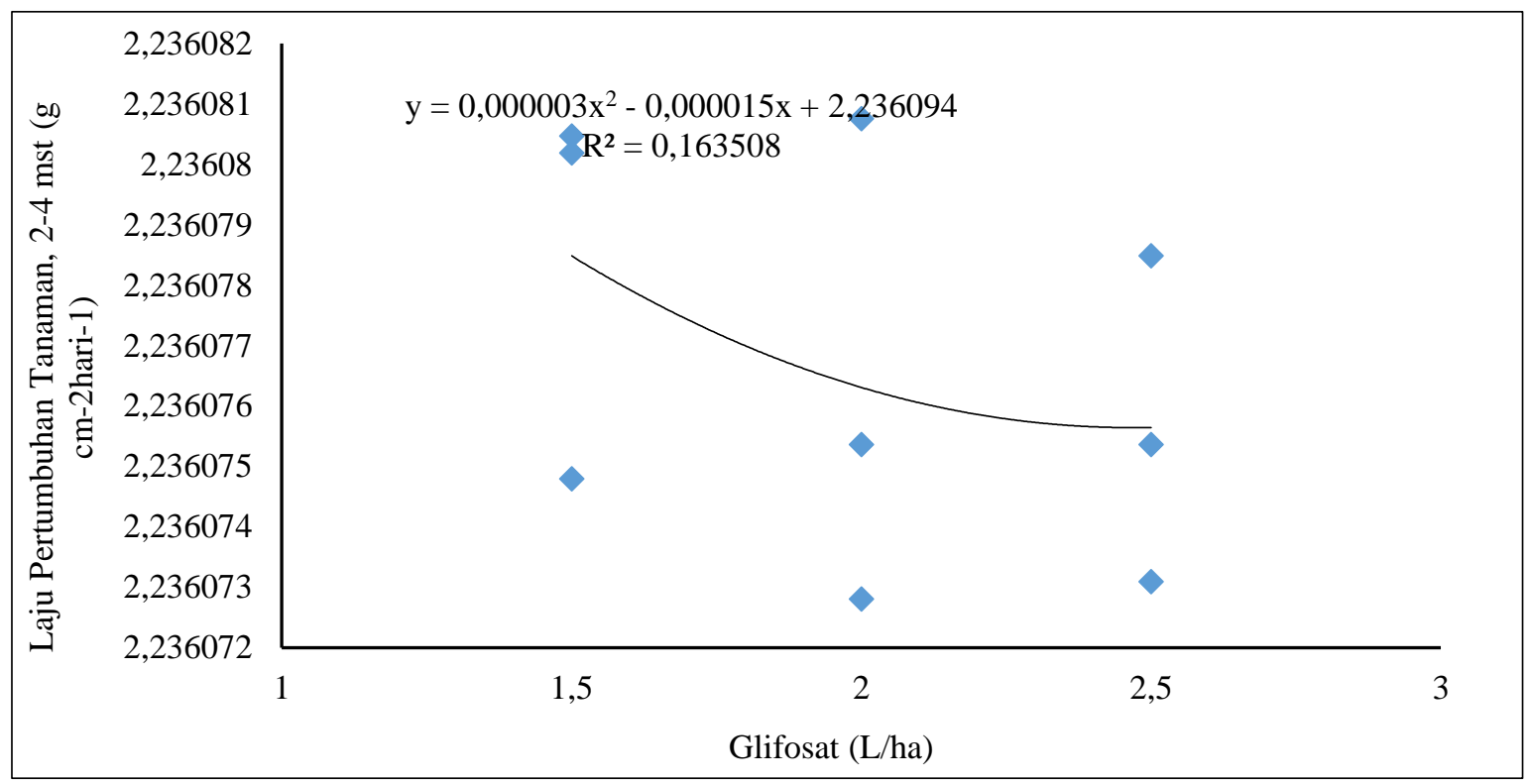

Gambar 5. Hubungan dosis glifosat dan laju pertumbuhan tanaman jagung

\section{Berat Tongkol Layak Jual}

Hasil analisis ortogonal kontras pada berat tongkol layak jual menunjukan bahwa pada peningkatan dosis herbisida glifosat 1,5 L/ha sampai 2,5 L/ha meningkatkan berat tongkol layak jual dengan pola garis $\mathrm{y}=$ -
$69.49 x^{2}+279.0 x-159.0\left(R^{2}=0.153\right)$. Dosis glifosat optimum $2.018 \mathrm{~L} / \mathrm{ha}$ dengan berat tongkol layak jual maksimum $129.408 \mathrm{~g}$ (Gambar 2 ).

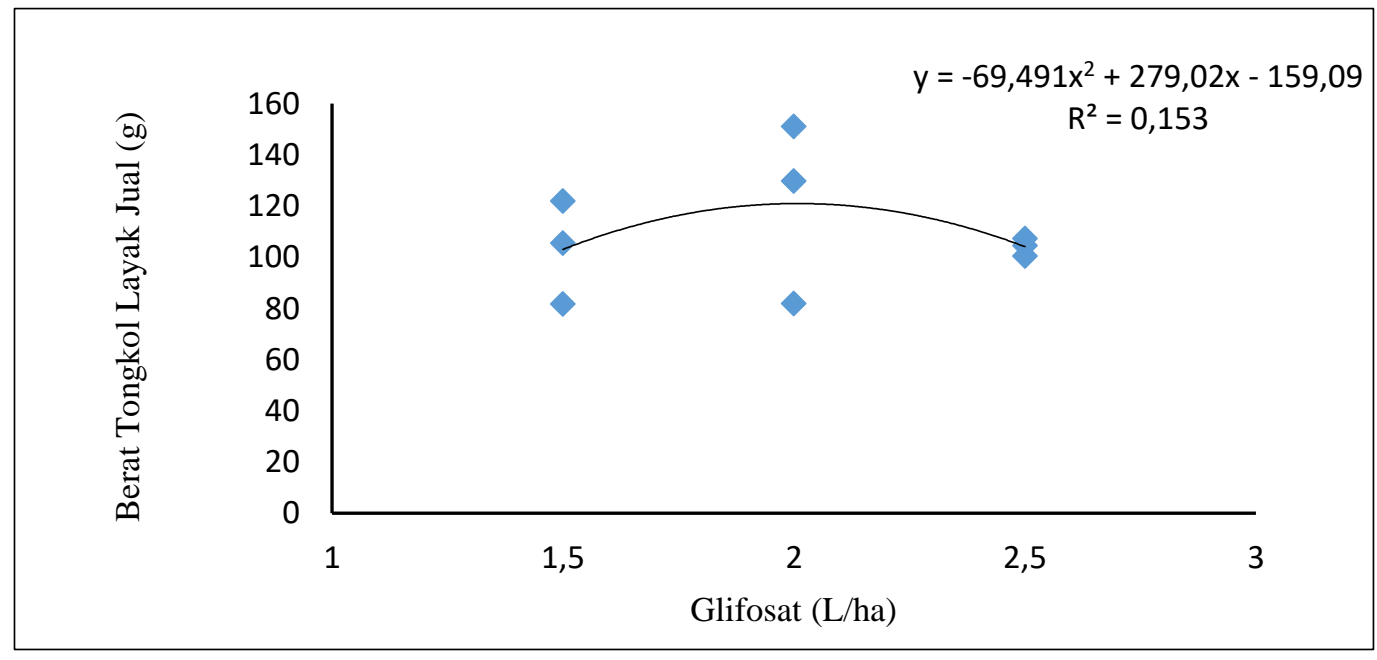

Gambar 8. Hubungan dosis glifosat dan Berat tongkol layak jual tanaman jagung manis 
Hasil BTLJ yang diamati peningkatan dosis herbisida mempengaruhi BTLJ sampai dosis tertentu yaitu 1,5 L/ha sampai 2.018 L/ha memberikan BTLJ $129.408 \mathrm{~g}$ ini tertinggi dari perlakuan lain. Diduga selain herbisida dapat menekan pertumbuhan gulma karena waktu paruh glifosat dalam tanah selama 60 hari, juga adanya kanopi tanaman yang sudah saling menutupi satu sama lain berakibat gulma tidak dapat tumbuh dengan baik sehingga penyerapan unsure hara lebih intensif tanaman jagung manis. Penyerapan hara yang lebih intensif berakibat baik terhadap perkembangan tongkol layak jual.

Peningkatan dosis herbisida glifosat yang semakin tinggi justru menurunkan hasil jagung yaitu peningkatan herbisida diatas $2.018 \mathrm{~L} /$ ha sampai $2,5 \mathrm{~L} /$ ha cenderung menurunkan berat tongkol layak jual. Adanya peningkatan dosis herbisida berakibat terhadap pengendalian gulma kurang efektif, herbisida glifosat efektif mengendalikan gulma daun lebar pada dosis rendah (Sukman dan Yakup, 1991). Sementara di lahan penelitian banyak dijumpai gulma kacang-kacangan sehingga aplikasi glifosat dengan dosis yang semakin meningkat tidak efektif menekan pertumbuhan gulma daun lebar. Gulma yang masih aktif tumbuh akan berkompetisi dengan tanaman pokok sehingga akan mempengaruhi hasil khususnya tongkol layak jual.

\section{KESIMPULAN}

Penggunaan herbisida campuran glifosat dan 2,4-D mampu menggeser komposisi gulma dengan nilai $\mathrm{C}$ sebesar $68,75 \%$ pada saat 2 hari sebelum panen. Herbisida glifosat dosis $1,5 \mathrm{~L} / \mathrm{ha}$ mampu menghasilkan laju pertumbuhan tanaman sebesar $2.23607813 \mathrm{~g} \mathrm{~cm}^{-2}$ hari $^{-1}$, dan berat tongkol layak jual 129,408 g.

\section{DAFTAR PUSTAKA}

Badan Pusat Statistik (BPS). 2013. Produksi Tanaman Jagung manis di Indonesia. http://www.bps.go.id/tnmn_pgn.php?k $a t=3 \& i d$ subyek $=53 \&$ notab $=0$. Diakses 29 September 2014.
Faqihhudin, M.D., Haryadi, dan H. Purnamawati. 2014. Penggunaan Herbisida IPA Glifosat terhadap pertumbuhan, hasil dan residu pada jagung. Jurnal Ilmu Pertanian 17 (1) : $1-12$.

Gomez, K. A., and A. H. Gomez. 1995. Statistical Procedures for Agricultural Research. International Rice Research Institute, Los Banos, Laguna, Philippines.

Kurnia, U. 2004. Prospek pengairan pertanian tanaman semusim lahan kering. Jurnal Litbang Pertanian. 23(4) : 130-131.

Landerdale, F.T. and Savannah. 1998. Spectrum Laboratories; Chemical Fact Sheet. Spectrum Laboratories, Inc. GA, USA. Chemical Abstract Number 1071836.

Mercado, B.L. 1986. Control of Imperata cylindrica. In. Proc. $2^{\text {nd }}$ weed Control in tropical Crpos. WSSP-SEARCHA. Los Banos. Philippina. P 268-278.

Moenandir, J. 1990. Fisiologi Herbisida. Rajawali Press, Jakarta.

Paiman, P. Yudono, D. Indradewa dan B. Sunarminto. 2012. Keragaman komunitas gulma pada berbagai kedalaman tanah. http://upy.ac.id/agroekoteknologi/files/ keragaman\%20komunitas\%20gulma.p df. Diakses 2 oktober 2015.

Sembodo. D. R. J. 2010. Gulma dan Pengelolaannya. Graha Ilmu, Yogyakarta.

Sukman dan Yakup, 1991. Gulma dan Teknik Pengendaliannya. PT. Raja Grafindo Persada. Jakarta.

Umiyati, U. 2005. Sinergisme campuran herbisida klomazon dan metribuzin terhadap gulma. Agrijati. 1 (1) : 1-2. 
Utomo, D.W.S., A. Nugroho, dan H.T. Sebayang. 2014. Pengaruh aplikasi herbisida pra tanam cuka (C2h4o2), Glifosat dan Paraquat pada gulma tanaman kedelai (Glycine max L.). Jurnal Produksi Tanaman 2(3).

Zubaidah, Y., Z. Lamid, Ridwan dan R. Suranto. 2001. Pemanfaatan herbisida glifosat selama 13 musim tanam pada sawah tanpa olah tanah terhadap sifat fisik dan kimia tanah. Prosiding Konferensi Nasional. XV Himpunan Ilmu Gulma Indonesia. Suroto, D., A. Yunus., E. Purwanto., Wartoyo dan Supriyono (ed), Surakarta, 17-19 Juli 2001. 